\title{
Geometrical Characteristics of Handwritten Suicide Notes An Exploratory Case Study
}

Israel Oron (Ostre), Ph.D.

Psychologist,

Independent Practice

ISRAEL

Correspondence: ostoris@gmail.com 


\section{Abstract}

Aim of study: to measure change in the geometric elements of the handwriting of individuals who died by suicide, detectable in handwritten suicide note when compared with material they wrote before the note.

Method: handwritten material of two males and two females who died by suicide were sampled from the author's professional archive, comprising three suicide notes and one personal diary, and a sample of each person's handwriting prior to the suicide note. For the purpose of geometrical measurements seven handwriting features were chosen from the forensic practice of analyzing handwritten documents. (The written material is in Hebrew, but the research focus is on geometric manifestations and not content).

Results: measured changes in the seven handwritten features were found to differentiate suicide notes from the way of writing in the pre-note material and are visually presented.

Conclusion: changes in handwriting could contribute in future to the process of detecting suicidal individuals before the very first self-harming act is inflicted.

Keywords: handwritten suicide notes, geometrical analysis, risk-assessment 


\section{Introduction}

Analyzing the content of suicide notes to gain insight into a suicidal frame of mind is already an acceptable method among professionals. Yet, I suggest that handwritten notes also include valuable characteristics that are not content related, but nevertheless could improve our understanding of the suicidal mind. In particular they could contribute to the process of suicide-risk assessment. These characteristics are measurable geometrical qualities such as the size and shape of letters and words; the distance between letters and between words; the spatial alignment of the content along the surface of a paper. The article will explain and illustrate the expected contribution of these geometrical qualities to suicide-risk assessment.

Handwriting is the production of writing strokes and the overt manifestation of divergent cognitive, psychomotor and biophysical processes (Van Galen, 1991). Handwriting is systematically taught from the start of formal teaching, and even nowadays, despite the increase in technology, it is common for children to learn how to write by hand. Indeed, learning how to write is one of the most important things a child will do when he or she begins school, which involves becoming familiar with the letters of the alphabet, mastering the pen strokes used to form letters, and practicing to hold the pen or pencil in a tripod grip (Alston and Taylor, 1987; Sassoon, 1986). It is common for new writers to struggle with letter formation, spacing and posture in the beginning, but teachers are trying to improve the technique as well as the layout of content.

It is a known fact that even children, who learn to write from the same teacher and by the same particular handwriting model, soon develop an individual mode of writing. The emergence of individuality occurs when children begin to enjoy the act of writing, when their actual letters reflect a more relaxed attitude, and when their personal handwriting gains in speed and confidence to enable them to express their thoughts freely and legibly on paper (Sassoon, 1990, 1993; Schwellnus et al., 2012). A person's unique mode of writing remains discernible throughout his/her life, and there are significant differences between the handwritings of different persons (Huber and Headrick, 1999; Morris, 2000; Smits et al., 2002).

In handwriting analysis two types of methods are employed: static and dynamic. Static characteristics of handwriting are the ones that can be analyzed after the 
writing process, while dynamic features concern characteristics of handwriting that are analyzed during the writing process.

Typical tools of the dynamic method are digitizing tablets and electronic pens, through which one can measure not only temporal and spatial variables of handwriting but also the pressure exerted over the writing surface as well as pen inclination and pen orientation. Moreover, these devices can capture pen movement not only while the pen is in contact with the writing surface but also when the pen is in close proximity to the surface ("in-air").

In the static method, the focus is on quite a few geometric characteristics: alignment (the spatial organization of the writing); baseline (the imagery or actual line on which the writing rests); slope of letters (as measured by the angle against the baseline); area of margins (the relative spacing of the four margins); shape and size (of letters, words, and the general alignment); spacing (distance between words, letters, lines); pressure applied when writing (as measured by the depth of the strokes) (Huber and Headrick, 1999; Morris, 2000).

In essence, handwriting and drawing are both graphic means of expressing behavior, but psychologists have been willing to use drawing as a means of assessing behavior of individuals (e.g., Machover, 1949; Goodenough, 1954) and reluctant to use handwriting (Lester, 1981). Lester conclusively suggests that there are no sound reasons to ignore handwriting as a source of information about people, providing that it is conceptualized in valid psychological terms and proper methodological research designs.

A few psychologists and related professionals have explored the question whether there is an association between a number of isolated and well-defined handwriting features with specific personality and behavioral traits.

For example, if handwriting problems persist beyond a certain age in elementary school, it might be a sign that the cause of the problems is more serious than simple technical obstructions. In such cases the written trace can be used by experts in the pedagogy of handwriting as an aid to assessment, often revealing a child's underlying difficulty (Sassoon, 2003). Thus, handwriting can sometimes provide vital clues to certain medical conditions such as developmental coordination disorder (Rosenblum and Livneh, 2008), or visual problems, when irregularly spaced letters may indicate that a child cannot see well enough to space them properly. Another example is illegible handwriting that may indicate dyspraxia, a coordination problem 
when the learner is struggling with fine motor skills which makes holding a pen or pencil very painful (Sassoon, 2003). Dyslexia is another learning disability reflected in handwriting, by spelling mistakes and by a messy work with plenty of corrections and erasure marks.

With regard to adults, Rispler and colleagues (2018) examined the relationship between handwriting and mood, and found that handwriting strokes made by people in a negative mood had shorter width and height in comparison to those made in a positive or neutral mood. (A stroke is a line made by a single movement of a pen. Different combinations of strokes are used for producing letters and numbers). Research on the effect of alcohol on handwriting has revealed that the following parameters increased significantly under its effect: word lengths; height of upperand lower-case letters; height of ascending letters; height of descending letters; spacing between words (Asicioglu and Turan, 2003).

Another study has focused on the obsessive-compulsive condition (Mavrogiorgou et al., 2001). By employing the dynamic method of analysis, it found that participants with OCD had significantly lower peak velocity while writing, and handwriting strokes were shorter, reflecting micrographia.

Mergl and his associates (2004) concluded that depressed persons wrote slower than others (in the control group) as reflected by stroke duration.

To the best of my knowledge, apart from the Hebrew version of this article (Oron, 2017), only one study has so far been published (Aşıcıoğlu, 2017) presenting an analysis of how a suicidal decision affects the handwriting in notes. Aşıcıoğlu found that compared with handwriting of a control group, suicide notes contain more variation in space between words, and more frequent angular and tremor writing. (Example of angular writing: unusually right upstroke that replaces a lower loop in the letters $y$ and $g$, making an angular bottom. Tremor writing: it has a psychological basis, which gives rise to neuromuscular spasm and is expressed in task-specific activities such as writing).

The current study aims at contributing to the field of suicide-risk assessment by presenting measurable change in the geometric elements of the handwriting in handwritten suicide notes in comparison to material written before the notes. The geometrical change in these features could thus serve as an indirect risk factor of suicide. Hence, the current study is in line with the endeavor to identify several behavioral manifestations which could indirectly indicate suicidal intent. The common 
denominator of these manifestations is a sudden change in the routines and general behavior (Rudd et al., 2006). For instance, from being very sociable becoming more distant, aloof and reserved, or vice versa; giving away prized possessions; withdrawing from activities that previously were enjoyable; suddenly becoming less concerned about one's personal appearance. But please note, that these behaviors do not necessarily and conclusively point to a suicidal intent. Instead, each one of them indicates some degree of probability that suicidal intent is in force which should attract attention and close watch, and be confirmed or refuted by professionals. In essence, such a process shares a similar principle with the hypothesis testing procedure, namely, whether to accept or to reject the preliminary and the cautious hypothesis that the person in question is suicidal. By contrast, there is obviously no need to search for indirect indicators, when direct ones are identified, as for example, when a person talks about suicide; is researching suicide methods; buys suicidal materials; writes a suicide note; attempts to kill or to harm himself/herself (NIH Website, 2020).

The presented study is the first step toward the inclusion of handwriting transformations as one more indirect indicator of suicide risk. In this respect it is an exploratory search for preliminary evidence supporting the inclusion.

\section{Aim of the Study}

The present study is meant to provide a few visual examples of measured geometric changes displayed in handwritten suicide notes composed by males and females who killed themselves. The changes were discerned by comparing suicide notes with the mode of writing found in material composed prior to their last words. My study thus provides the first insight into the issue and suggests that handwriting transformations (in any language) could contribute to our ability to detect suicidal individuals before their very first self-harming act is inflicted.

In addition, and incidental to the main results of the study, I will comment critically in the Discussion and the Appendix below on the method graphologists have employed to analyze suicide notes. 


\section{Method}

\section{Research design}

Since no study has been published yet concerning a comparison of handwriting characteristics of texts written before and after individuals take their lethal decision, the research design applied was the exploratory case study, geared to gain familiarity with this yet unknown phenomenon and to prove that further investigation is warranted. The design permits to select a limited number of participants for study and is meant to open up the door for further examination of the phenomenon observed (Thomas, 2011). In the current study the observed data is illustrated visually by presenting the participants' mode of handwriting, thus enabling readers to gain direct impression by themselves.

The current study employs a before-after methodological approach, an approach usually used when a certain condition is measured before and after an intervention, in order to learn the effect of that intervention. Here a one-group pretest-posttest design was employed (Price et al., 2017), which consists of a single group of individuals who took their own lives. The effect of the suicidal decision on handwritten suicide notes was assessed by measuring the changes of specific geometric handwriting features detected in suicide notes.

\section{Method of sampling}

Material was sampled by the purposive sampling method. It is a non-random method when a deliberate choice of the units to be studied is done, that relies on the judgement of the researcher (Sharma, 2017). The method is appropriate for the current study considering its aims and since it is in its initial, exploratory stage, where the focus lies on exemplified cases and on determining whether or not a more indepth study is warranted (Etikan et al., 2015).

\section{Sample}

Writing material of two men and two women were sampled from my professional archive. The material comprised of three suicide notes and one personal diary, and a sample of each person's handwriting prior to the suicide note, all written during the 1980s and 1990s. In all four cases, the police investigation verified unequivocally that they died by suicide. 


\section{Language of the notes}

The written material is in Hebrew, which is characterized by the following points (based mainly on Yochman and Parush, 1998).

The alphabet runs from right to left, contains 22 consonantal letters in cursive and in block (print) style, and six final cursive letters. Hebrew has no capital letters, and cursive letters are not joined together. The vowels (not an integral part of the script) appear as lines and dots above or below the script. Thus, the writer processes two different directions of flow (right to left and up and down), necessitating a change in rhythm. Furthermore, numbers, which are identical to English, are written from left to right, meaning that the writer has to change direction if numbers are to be incorporated. As a result, it is hard for a continuous flow to develop, and the writer needs to concentrate harder and invest more energy.

(Please note that unfamiliarity with Hebrew is not a hindrance to following my elaboration below, since the focus is on geometric manifestations and not content).

\section{Operational definitions}

Suicide note: the final message written and left behind by someone who afterwards died by suicide, irrespective of whether that message is addressed to a specific person or not.

Handwriting change: the research focus is on quantitative handwriting features in the suicide note which are at least twice more, or twice less than the same features in the material written prior to the note.

The following features were measured, based on the forensic practice of analyzing handwritten documents (Huber and Headrick, 1999; Morris, 2000; Koppenhaver, 2007):

1- Distance of the four page-margins of a page from the respective side of the written area;

2- Distance (space) between lines;

3- Distance (space) between letters;

4- Distance (space) between words;

5- Size of letters or words;

6- Slant of letters or words;

7- Shape of letters or words; 


\section{Results}

Transformations in the above seven handwritten features were found to differentiate the handwriting mode in the suicide notes from the pre-note practice of writing. No difference was noted between males and females in this regard. Please note that each description of the following sampled material will exemplify only one or just a few of the features, except the personal diary.

\section{Case-Study $A$}

A woman, age 38. Suicide note addressed to her husband.

Figure 1: Suicide note (on the right) and compared material
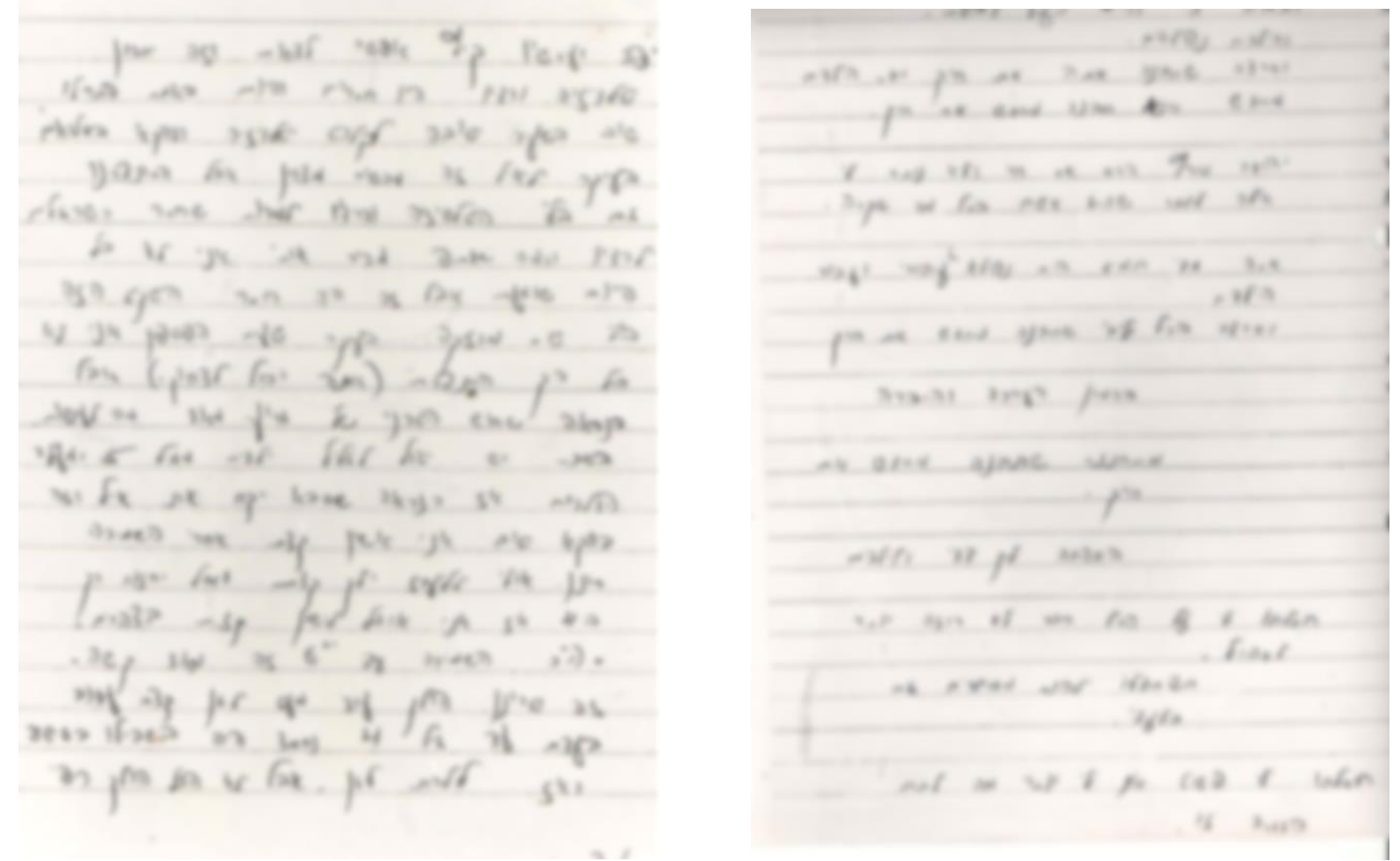

On first sight already, one can clearly observe a change in the alignment of the text in the suicide note. Habitually her writing extended over each line in full from the right side to the very end of the left one. But, in the suicide note she has left considerable space on the right margin, as well as on the left one. In addition, the points of first stroke on each line (on the right side) are erratic. Starting at $36 \mathrm{~mm}$ distance from the right edge of the page up to 40 and $80 \mathrm{~mm}$, then reduced to $33 \mathrm{~mm}$ and up again to $43 \mathrm{~mm}$. Skipping over lines and thus leaving free lines, is another characteristic. 


\section{Case-Study B}

Male, age 21. Suicide note addressed to his family.

Comparison between the suicide note and the writer's habitual mode of writing (Figure 2) shows that the size of the entire script decreased by three times on average.

Figure 2: Suicide note (right) and compared material
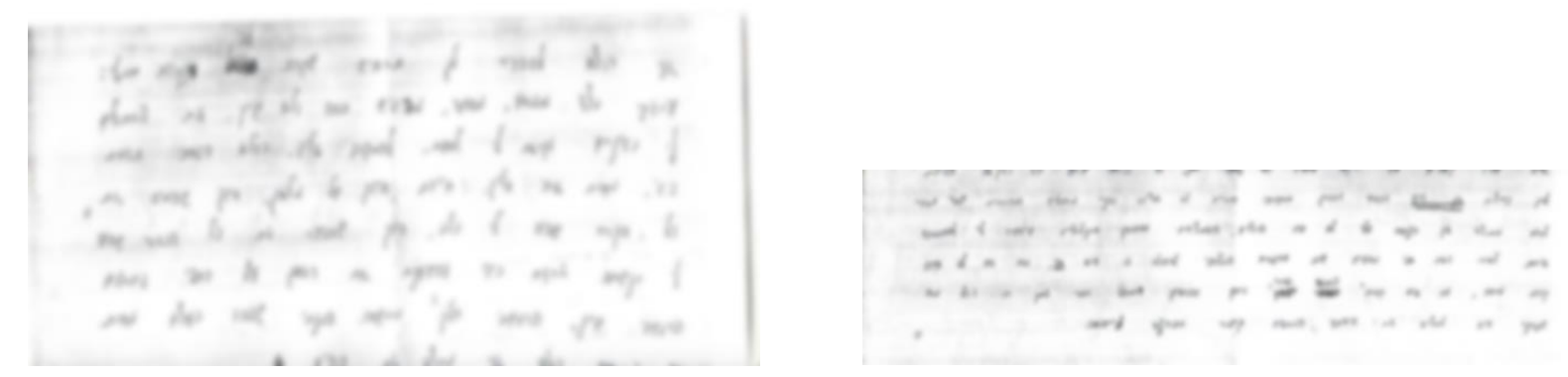

In the next figure (Figure 3) a few unblurred words from the suicide note are presented (top, white background), compared with words written before the writer arrived at his lethal decision.

Figure 3: Comparison of specific words

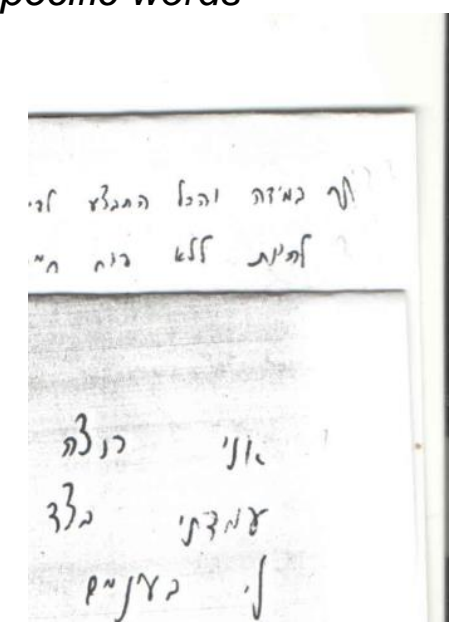

\section{Case-Study C}

Female, age 29. Suicide note addressed to parents.

This young woman reached a crossroad in her life and in the course of writing down her conflicts and her reflections on critical life events she considered to kill herself. $A$ few weeks later, she left behind a message to her parents, in which she declared her 
intent to kill herself, and left home. But, on her way she changed her mind and phoned mother asking to fetch her and take her home. After a short while she left another note and executed her suicidal plane. That means, three suicidal scripts were written, but the suicide note proper was the last one, since she killed herself afterwards. This note is compared here with the first script.

Figure 4: Suicide note (right) and first message

Even in the blurred image, a comparison immediately give the impression that the two texts were written by two different persons. Letters in the left piece of writing are characterized by a full and thick shape, compared with the thin and thread-like shape in the suicide note, as is illustrated in Figure 5 with regard to individual letters. On the left, please compare the third letter (from the right) in the upper word (taken from the suicide note) with the first letter in the word just below (the same Hebrew letter in both cases). Or, on the right side of the figure, pay attention to the first letter (from the right) in the upper word (from the suicide note), and to the first one in the word below (again, in both cases, the same Hebrew letter). The change is self-evident. 
Figure 5: Comparison of specific words
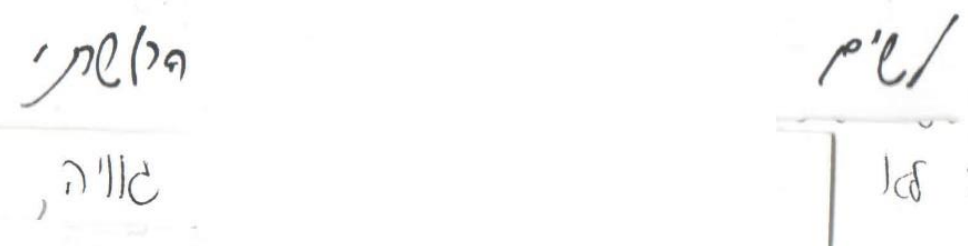

Another characteristic in the suicide note is a decreased degree of letters' slant to the right, compared with the previous writing (on average $62^{\circ}$ and $79.5^{\circ}$, respectively). Increased distance between lines also characterizes the suicide note $(15 \mathrm{~mm}$ against $6 \mathrm{~mm}$ ). As to the alignment, following the first stroke on the first line in the suicide note, each of the following five lines is increasingly indented: $6 \mathrm{~mm}, 7$, 10,15 and $17 \mathrm{~mm}$, respectively. In the compared material, indentation is completely absent.

\section{Case-Study D}

Male, age 20. Personal diary.

The content of a personal diary written by a suicidal person is valuable for following his/her thread of thoughts and learning how suicidal ideation is gradually built up and crystallized into a practical plan. The same holds true for the geometric features of that person's handwriting.

This young adult recorded personal events and his innermost thoughts for nearly ten months, up to the very day he died by suicide. The final page in the diary is, in fact, a suicide note which says: "I have decided to put an end to my life, [signed] Anonymous" (five words in Hebrew).

Figure 6 presents a comparison of this note with the first page in the diary. Comparison reveals that as opposed to the first page, the very first stroke in the note was done on the fourth line and not on the first one. Besides, between the three written lines in the note the writer has left free lines. Another distinguishing feature is that while on the first page words are aligned all along the (ruled) lines from the right side to the very end of the left one, none of the three written lines in the note shows such a layout. In addition, the average size of the letters in the note is twice as big. Moreover, the distance between words is much larger in the suicide note $(16.5 \mathrm{~mm}$ as against $8.2 \mathrm{~mm}$ ). Another characteristic is a slant to the right: $65^{\circ}$ in the suicide note as against $88^{\circ}$ in the compared material. 
Figure 6: Suicide note (right) and first page of the diary
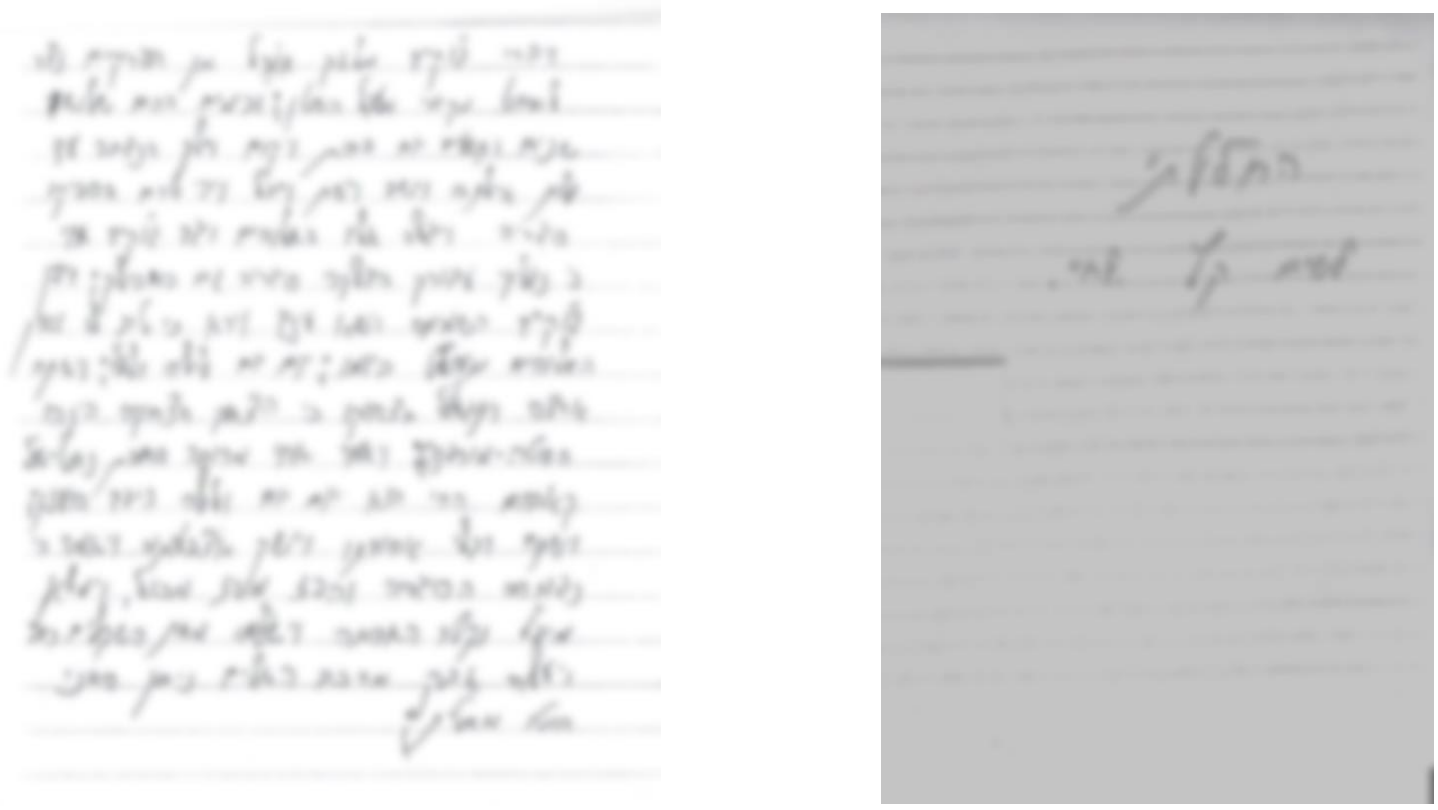

Comparison reveals that as opposed to the first page, the very first stroke in the note was done on the fourth line and not on the first one. Besides, between the three written lines in the note the writer has left free lines. Another distinguishing feature is that while on the first page words are aligned all along the (ruled) lines from the right side to the very end of the left one, none of the three written lines in the note shows such a layout. In addition, the average size of the letters in the note is twice as big. Moreover, the distance between words is much larger in the suicide note $(16.5 \mathrm{~mm}$ as against $8.2 \mathrm{~mm}$ ). Another characteristic is a slant to the right: $65^{\circ}$ in the suicide note as against $88^{\circ}$ in the compared material.

On the whole, the note gives an impression of an announcement, a declaration, in which its producer added visual aspects to the text in order to emphasize its meaning mainly for himself, since it concluded a prolonged suicidal conflict with no solution, as was discussed in the previous pages of the diary.

Three months after the first page of the diary had been written, the young adult suddenly wrote in quite two quite different handwritings on the same page (Figure 7). 
Figure 7: Opposed handwritings (a)

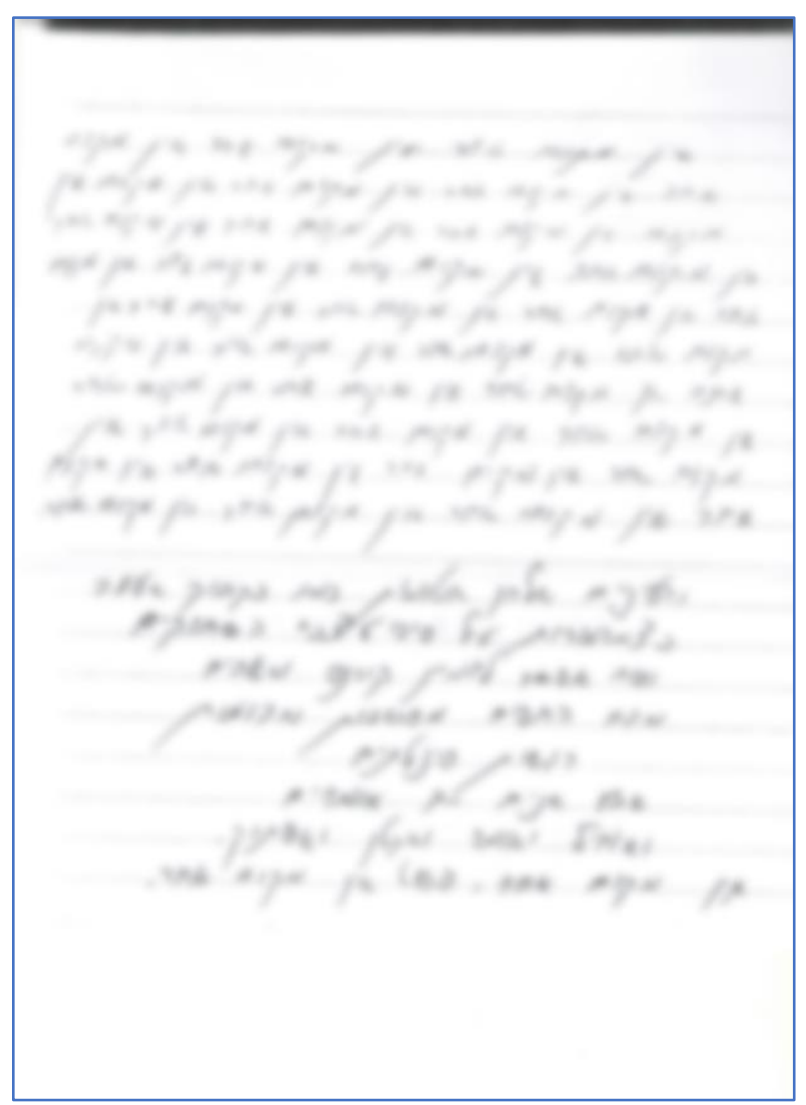

The upper paragraph shows a considerable change in handwriting not only compared with the first page of the diary, but also compared with the second half of the above page. The geometrical change is clearly illustrated in Figure 8, comparing the size of the opening three words (from the right) in the upper paragraph (first line) with the size of the same three words on the last line of the page.

Figure 8: Comparison of specific words

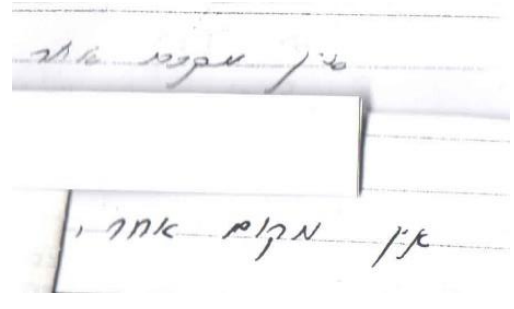

In addition, it is quite obvious that handwriting in the second half of the page (Figure 7) did not resume exactly to the mode of writing in the first page, nor to the same alignment (Figure 6, left). 
It should be pointed out that the page (Figure 7) was written following the writer's attempt to figure out a "nightmarish dream" from which he woke up "in cold sweat", as he described it in his diary.

A similar writing event occurred about a month before his death. In that case a more impressive change in writing is recognizable. As in the previous example, here too the writer divided the page into two parts. The first one was written in a very illegible and disorganized handwriting (Figure 9, the upper two lines). But soon after the writer had concluded to write this part, he resumed to write in his (relatively) ordinary mode (Figure 9, the two closing lines).

Figure 9: Opposed handwritings (b)

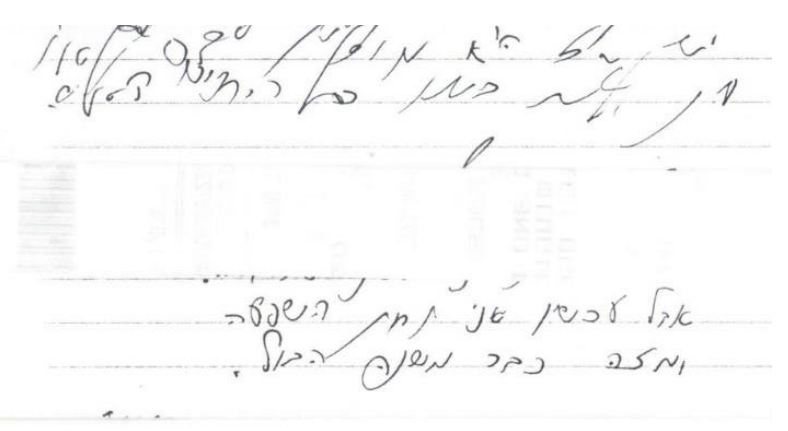

On the upper lines, letters are not written while keeping a straight course along the line. Instead, some letters do not rest on the baseline but seem to hover above it, and others are penetrating the upper or the lower ruled line. Moreover, the shape of most of the letters is distorted compared with the shape in the second part. On the pages that followed, handwriting resumed to its habitual mode, up until the final page of the diary.

This illegible paragraph was written by the young adult following several days of trying to solve a tormenting dilemma, whether to kill himself or to continue to live an unbearable life with no prospect of improvement.

\section{Discussion}

By applying geometrical measurements to analyze transformations in suicidal handwriting, the aim of the current study is met. The visual illustrations clearly shed light on the suggestion that indeed changes are detectable in the handwriting of individuals who are composing their last words. 
An exploratory case study should be followed by a study on a larger scale. The current results warrant replication and refinement in larger samples written by suicidal males and females. These prospective studies should aim to discern whether men and women differ in regard the seven characteristics, and to search for additional ones. The findings should be helpful to formulate a set of well-defined measured characteristics of change and their interactions, to be used as indirect indicators for identifying suicidal individuals. That is to say, the proposed set would be routinely used to identify such individuals by analyzing their handwriting, when their suicidal intent is not yet revealed (by direct indicators such as writing a suicide note). For instance, analyzing messages written at work, or private correspondence with a family member or a friend.

In this connection it is important to emphasize once more that detecting changes in the handwriting of individuals is opened to further examination in order to infer conclusively a suicidal intent, as it is done by the hypothesis testing procedure. For instance, detecting a sudden decrease in the size of words (see Case-Study B) may only introduce a hypothesis of suicidal writing, since such a decrease is also characterizing physical illness such as Parkinson (Smits et al., 2014) as well as obsessive-compulsive condition (Mavrogiorgou et al., 2001). Obviously, the hypothesis testing principle in this regard also emphasizes the importance of formulating a proper set of handwriting features, instead of relying on just one or two features. And finally, a comment regarding the approach to suicide notes employed by graphologists. As described in the Appendix, they did not succeed in proving their claim that they are competent to recognize a suicidal character just by inspecting a person's handwriting. Moreover, they have refrained from specifying on what handwriting characteristics they have based their conclusion that notes in question have been written by individuals who killed themselves.

By contrast, in the geometrical handwriting analysis presented here, the handwriting features are explicitly specified and measured. Not less important, these detected seven features should not be considered as characterizing exclusively suicidal handwriting.

In the light of the results presented here, implementing geometrical measurements to analyze transformations in supposed suicidal handwriting could improve the process of assessment. 


\section{References}

Alston J, Taylor J (1987), Handwriting: Theory, research and practice. New York: Nichols Pub. Co., Ch. 11

Aşıcıoğlu F (2017), Contents and medico-legal aspects of suicide notes: Turkey sample, Suicidology Online , 8 (1), pp. 38-48

Asıcıoglu F, Turan N (2003), Handwriting changes under the effect of alcohol, Forensic Science International, 132, pp. 201-210

Etikan I, Musa SA, Alkassim RS (2016), Comparison of convenience sampling and purposive sampling, American Journal of Theoretical and Applied Statistics, Vol. 5, No. 1, 2016, pp. 1-4

Frederick CJ (1968), An Investigation of handwriting of suicide persons through suicide notes, Journal of Abnormal Psychology, 73(3), 263-267

Goodenough FL (1954), Measurement of intelligence by drawings, World Book Company, Chicago, USA

Huber RA, Headric AM (1999), Handwriting Identification: Facts and Fundamentals, CRC Press, chs. 3, 6, 9

Koppenhaver KM (2007), Forensic Document Examination: Principles and Practice, Humana Press Inc. Chap. 2, 3, 10

Lester D (1981), The psychological basis of handwriting. Nelson-Hall, Chicago, USA

Machover K (1949), Personality projection in the drawing of the human figure, Springfield: Thomas

Mavrogiorgou P, Mergl R, Tigges P, El Husseini J, Schröter A, Juckel G, Zaudig M, Hegerl U (2001), Kinematic analysis of handwriting movements in patients with obsessive-compulsive disorder, Journal of Neurology, Neurosurgery and Psychiatry, 70, pp. 605-612

Mergl R, Juckel G, Rihl J, Henkel V, Karner M, Tigges P, Schroter A, Hegerl U (2004), Kinematical analysis of handwriting movements in depressed patients, Acta Psychiatrica Scandinavica, 109, pp. 383-391

Morris R (2000), Forensic handwriting identification, Academic Press, USA ch.3, 4. 5-8

Mouly S, Mahé I, Champion K, Bertin C, Popper P, De Noblet D, Bergmann JF (2007), Graphology for the diagnosis of suicide attempts: A blind proof of principle controlled study, International Journal of Clinical Practice, 61(3), pp. 411-5

$\mathrm{NIH}$ (2020), National Institute of (Mental) Health, USA https://www.nimh.nih.gov/index.shtml

Oron (Ostre) I (2017), How a suicidal decision affects the content and the handwriting in suicide notes, (Hebrew). The website of the Israel Psychological Association 
Price PC, Jhangiani RS, Chiang I-CA, Leighton DC, Cuttler C (2017), Research Methods in Psychology, 3rd American Edition ch. 8

Rispler C, Luria G, Kahana A, Rosenblum S (2018), Mood impact on automaticity of performance: handwriting as exemplar, Cognitive Computation, 10, pp. 398-407

Rosenblum S, Livneh-Zirinski M (2008), Handwriting process and product characteristics of children diagnosed with developmental coordination disorder, Human Movement Science, 27, pp. $200-214$

Rudd MD, Berman AL,Joiner TE, Nock MN, Silverman MM, Mandrusiak M, Van Orden K, Witte T, (2006), Warning signs for suicide: Theory, research, and clinical applications, Suicide and Life-Threatening Behavior, 36(3), pp. 255-262

Sassoon R (1986), A handwriting for life, Child Language Teaching and Therapy, 2(1), pp. 20-30

Sassoon R (1990), Handwriting, Stanley Thornes Pub., England.

Sassoon R (1993), The art and science of handwriting, Intelect Books, Oxford.

Schwellnus H, Carnahan H, Kushki A, Polatajko H, Missiuna C, Chau T (2012), Effect of pencil grasp on the speed and legibility of handwriting in children, American Journal of Occupational Therapy, 66, pp. 718-726

Sharma G (2017), Pros and cons of different sampling techniques, International Journal of Applied Research, 3(7), pp. 749-752

Smits EJ, Tolonen AJ, Luc Cluitmans L, van Gils M, Bernard A. Conway BA, Srihari SN, Cha SH, Arora H, Lee S (2002), Individuality of handwriting, Journal of Forensic Sciences, 47(4), 856-872

Smits EJ, Tolonen AJ, Cluitmans L, van Gils M, Conway BA, Zietsma RC, Leenders KL, Maurits NM (2014), Standardized handwriting to assess bradykinesia, micrographia and tremor in Parkinson's Disease. PLoS ONE 9(5): e97614

Thomas $\mathrm{G}$ (2011), A typology for the case study in social science following a review of definition, discourse, and structure, Qualitative Inquiry, 17(6) 511-521

Yochman A, Parush S (1998), Differences in Hebrew handwriting skills between Israeli children in second and third grade, Physical \& Occupational Therapy In Pediatrics, 18(3-4), pp. 53-65

van Galen GP (1991), Handwriting: Issues for a psychomotor theory, Human Movement Science, 10, 165-191 
Appendix: Graphology and Suicide Notes

To the best of my knowledge, two studies have so far been published concerning graphologists' claim that they are competent to identify suicidal intent by inspecting handwritten material. In both of these studies the graphologists have failed to prove their claim.

\section{Frederick (1968)}

Forty five suicide notes, handwritten by males and females, were copied by different control writers, and each of the original notes was then coupled with three control notes. Thus, a total of 180 notes comprising 45 sets were reached, and a four-choice method of selection was used. Three sets of five judges were used: graphologists, detectives, and secretaries. Each judge was asked to discern which of the four notes in each set was an original suicide note, according to the handwriting. In other words, experienced graphologists were chosen to serve as experimental-judges and asked to identify original suicide notes. By employing the binomial expansion probabilities test, it was found that all the five graphologists exceeded chance expectation in selecting genuine suicide notes, while all of the control-judges did not. Specifically, the range of success for the graphologists was $55.5 \%-66.6 \%$, and the researcher conclusively declared that "factors in the handwriting of suicidal patients do reveal themselves to such an extent that genuine suicide notes can be selected by graphologists from notes written by other persons of the same age and sex". Yet, the research conclusion is open to challenge.

For one, from the instructions given to each of the three groups as well as from the content of the written material, it was obvious that the research deals with suicide. That is to say, it was clear for the participants that one out of four notes in each set was written by someone who killed him/herself and not by someone who is under some other kind of psychological condition. Therefore, the conclusion to be drawn from the research is that the graphologists were able to single out the genuine notes since they based their assessment on the different mode of handwriting in comparison to the control notes. In other words, their success was based on a unique experience of dealing with various, and occasionally odd, handwritings, rather than their knowledge of the features which characterize handwriting of suicidal individuals. My conclusion is supported by the fact that graphologists did not "state 
what clues operated in the handwriting per se which influenced their judgments. Despite the fact that the investigator had repeatedly urged them to be specific about possible clues in the handwriting, they resisted comments of this sort". In short, they have pointed out the right suicide note based on a general impression such as "writing appears disorderly", or "aimless", etc.

My conclusion is also supported by the fact that all the graphologists agreed correctly with regard to merely 14 out of 45 original notes (31\%). That means that each one of them made his assessment based on his subjective experience and impression, and not according to validated characteristics derived from a systematic and well-arranged research design.

\section{Mouly et al., (2007)}

Forty patients hospitalized in the intensive care unit of a general hospital for deliberate self-poisoning with drugs were asked to write a story or a short letter relating a childhood memory not linked to their suicidal act. The control group consisted of 40 healthy volunteers with no history of suicidal behavior and was given identical instructions as the former group. The letters from the patients and controls were then mixed. There were two independent teams of evaluators blind to the diagnosis: two graphologists and two physicians from an internal medicine unit without any knowledge about graphology. The evaluators were asked to classify the 80 letters as 'suicide' or 'no suicide'.

It was found that both teams classified the letters with significantly more effectiveness than chance. Moreover, there was no statistical difference regarding the accuracy of the evaluations between the graphologists and internists. Nonetheless, researchers concluded that they have "demonstrated the ability of graphologists to detect a particular psychiatric status". But in the course of the discussion, it was mentioned that such ability "was also detected by internists who were not graphologists, [which] could represent an argument against the specific and rigorous nature of this technique. But one may also consider that the principles of graphological diagnosis are based on good sense and a logic which is perceptible by non-specialists".

First of all, it is obviously clear that graphologists (claiming to be experts) did not 
classify the written material better than the internists. In addition, this research shares two shortcomings with the previous one. For one, the evaluators were asked to distinguish suicidal from non-suicidal handwriting. Thus, the graphologists only succeeded to single out the irregular handwritings and not the suicidal ones, based on their considerable acquaintance with a great number of various handwritings. Second, the graphologists were not able to specify graphic elements, on which their evaluation was based. 